\title{
Enhancing Students' Mathematical Problem-Solving Skills through Bar Model Visualisation Technique
}

\author{
Sharifah Osman ${ }^{1 *}$, Che Nurul Azieana Che Yang ${ }^{2}$, Mohd Salleh Abu ${ }^{1}$, Norulhuda Ismail ${ }^{1}$, \\ Hanifah Jambari ${ }^{1}$, Jeya Amantha Kumar ${ }^{3}$ \\ ${ }^{1}$ Universiti Teknologi Malaysia, MALAYSIA \\ ${ }^{2}$ SK Taman Perling, Johor, MALAYSIA \\ ${ }^{3}$ Universiti Sains Malaysia, MALAYSIA \\ *CORRESPONDENCE: $\bigotimes$ sharifah.o@utm.my
}

\begin{abstract}
Previous studies revealed that many students cannot perform well when it comes to word problem-solving questions. There are various problem-solving strategies that can be applied to help students to overcome the problem. Visualisation techniques in learning have been used to help students enhance their conceptual understanding of the mathematical problem-solving and the use of bar model visualisation technique is one of the strategies. This study aims to investigate students' achievement in mathematical problem-solving after applying the Bar Model and to explore students' experiences while applying the technique. This study employed a preexperimental design of the quantitative research. There were 32 participants of year three students. The instrument used in this research consists of questions of pre-test and post-test and a semi-structured interview. Data were analysed using SPSS 20.0 software and thematic analysis. The test results showed that there is a significant difference in participants' mathematical problem-solving achievement. The analysis of semi-structured interview transcripts revealed that level of understanding and motivation influence students' performance. Findings of this study showed that students perform better after the implementation of the Bar Model in mathematical problem-solving. This study can provide an alternative or guidance for teachers to improve students' mathematical problem-solving skills.
\end{abstract}

Keywords: problem-solving strategies, visualisation techniques, bar model, mathematical problem-solving skills

\section{INTRODUCTION}

Problem-solving is an important skill that one must have. Problem-solving in mathematics helps students to experience on how to solve daily life problems by applying their mathematical knowledge and skill. Word problem solving is one of the important components of mathematical problem-solving incorporates real-life problems and applications (Azizah, Rohani, \& Mokhtar, 2010). However, students cannot perform well in the examination when it comes to word problem-solving questions. Word problem solving is an area of difficulty and frustration for a considerable number of students (Bluman, 2005; Olga, 2010; Phonapichat et al., 2013; Verschaffel \& Corte, 1993). It can be seen on TIMSS and PISA results which were not good enough. Students face difficulties to understand the mathematical language and lead to misconception. In addition, students find it difficult to grasp the problem or some parts of it because of the mathematical language.

\footnotetext{
Article History: Received 23 July $2018 \bullet$ Revised 1 September $2018 \bullet$ Accepted 1 September 2018

(C) 2018 The Author(s). Open Access terms of the Creative Commons Attribution 4.0 International License (http://creativecommons.org/licenses/by/4.0/) apply. The license permits unrestricted use, distribution, and reproduction in any medium, on the condition that users give exact credit to the original author(s) and the source, provide a link to the Creative Commons license, and indicate if they made any changes.
} 
There are many factors that affected students' achievement in problem-solving. One of the factors is teacher pedagogical ways of teaching. Teachers still remain central to the teaching and learning despite using various methods (Martin, Khaemba, \& Chris, 2011 as cited in Han et al., 2013). Although there are many techniques and strategies existed to help students with problem-solving, there are teachers who still using the old teaching method and teacher-centred. Lack of conceptual understanding is happened due to inadequate exposure and use of thinking skills throughout the lesson. A teacher must adapt to the teaching that responds to the strengths and needs of all pupils (Mooney et.al, 2014). The teacher has to consider the needs of the children with different learning styles and abilities. Therefore, it is really important for teachers to change their ways of teaching based on students' needs and vary the strategies they taught to the students. It is vital for students to choose the best strategy when they attempt the word problem-solving questions.

According to Pehkonen et al. (2013), there was a need to develop teaching methods that correspond to the challenges set by constructivism. Teaching methods and strategies need to be changed to embrace $21^{\text {st }}$-century learning based on Constructivism theory. Constructivist approaches are central to this mathematics curriculum. To learn mathematics, children must construct their own internal structures (Government of Ireland, 1999). Not only in Ireland, it was agreed by all educators around the world; children must construct their own knowledge to have a meaningful knowledge to be applied in their daily life.

The aim of education is to acquire practical knowledge that sensible and meaningful for the life purpose. Students are supposed to learn and have problem-solving skills to be applied to their life. Problem-solving skills include analytical and critical thinking skills. These skills will help students in many ways especially in decision making. Problem-solving helps students to do reasoning in many aspects of life practice. Throughout the process of problem-solving, students will use their skills to analyse, brainstorm the solutions, determine the causes, evaluate possible strategies or solutions to confront or solve the conflicts and at the end implement the most effective solution. Mathematics is a potential medium to enhance the ability of students to engage in critical thinking and mathematical thinking through mathematical problem-solving ((Moussavi, 1998; Osman, Abu, Mohammad, \& Mokhtar, 2016). Mathematical problem-solving is one of the basic skills that can be measured and enhanced by several methods and techniques as well as the basic core in mathematics teaching and learning (Iyad \& Aslan, 2015). Visualisation acts as one essential component in mathematics problemsolving. Visualisation triggers students' imagination and deepens their understanding. It is not only limited to help students to visualise the question but also help to improve their thinking skill. By learning how to visualise the question, students can use this technique for another topic with problem-solving at any level.

Students' difficulties in problem-solving can be overcome through various strategies and activities (Vula \& Kurshunmlia, 2015). The bar model strategy is one of many problem-solving strategies that suitable to enhance students' understanding regarding word problem-solving questions. Bar Model is one of the visualisation ways of learning. Bar model is a strategy that was introduced in Singapore Education. Problemsolving skills teach students to be creative in solving the problems. The Singapore Math and Bar Model approach encourages greater problem-solving skills and creative thinking (Thirunavukkarasu \& Senthilnathan, 2014). Drawing in the Bar Model is a valuable tool for solving non-routine problems. Bar model enables students to see the number relationships, rather than focusing on the objects of the problems (Thirunavukkarasu \& Senthilnathan, 2014). Students need to draw a rectangle bar(s) to solve the questions. It is important to use teaching methods that require creativity from students (Arslan et.al, 2014). Bar model also inspires students to be creative when answering the questions as they need to draw a layout based on their understanding of the question. Research on mathematical drawing indicates a positive connection between drawing and problem solving (Edens \& Potter, 2007; Kamariah, Jennifer, \& Janette, 2016). Bar model is the strategy that helps students to construct their own knowledge. Its approach aligns with Piaget's (1974) constructivist theory that children construct their own knowledge through experience (Hofer, 2015). It is a model that fosters students' understanding regarding problem-solving questions. As the Bar Model is a visual approach, this model also nurtures critical thinking in students. By drawing the rectangular bar, students can extract information from the given question and look for pattern or relationship between the bar and information given. Marshall (2008) claimed that pictorial representations help students to visualise the abstract mathematics relationships. When the students get to visualise the question, it will enhance students' understanding of the questions. Students may use a representation (drawing) to scaffold their understanding of emerging concepts (Kamariah et.al, 2016). They can see the relationship between the information given and question requirement. This model-drawing technique is intended to enhance the conceptual understanding of the problem at the task (Olga, 2010). It helps students to visualise the question and take out all the information given when they draw the bar(s). Hence, the bar model is a suitable problem-solving strategy to 
teach the non-routine problems as it is helpful for students to transfer questions into a simpler and understandable form.

Therefore, this study aims to investigate students' achievement in mathematical problem-solving after applying the bar model and to explore students' experiences while applying the bar model in mathematical problem-solving. In order to meet the objectives of this research, the following research questions steer the study: i) What is the performance of students in pre-test and post-test before and after the implementation of the bar model? ii) Is there any significant difference in students' achievement in mathematics problem-solving after applying the bar model? iii) What are students' experiences while applying the bar model?

\section{METHODOLOGY}

This quantitative research employed the pre-experimental design. Samples were chosen based on convenience sampling. There was 32 Year 3 students involved in this study. There were two types of instruments used in this study; tests (pre-test and post-test) and semi-structured interview questions. There were ten questions of problem-solving under the topics of addition and subtraction. Those topics were chosen to apply the Bar Model as they are the basic operations in mathematics. Questions for pre and post-test were different, yet the level of difficulties of the questions was the same. Problem-solving questions consist of higher order thinking skills (HOTS) questions which were non-routine problem-solving questions. The semistructured interview focused on exploring the problems faced by students during answering questions of mathematical problem-solving using the bar model.

Participants answered pre-test questions before receiving the treatment, the bar model. The participants were given 50 minutes each to complete the test; 5 minutes for each question. The treatment was introduced after the participants have finished doing their pre-test. The treatment was conducted by introducing and teaching students the application of bar model in problem-solving of addition and subtraction and then followed by the post-test that was carried out after giving the treatment in three different sessions for a week. Nine participants were chosen based on their post-test marks and interviewed by the researcher. Data were analysed based on the instruments applied. For the pre and post-tests, data were analysed using paired Ttests through SPSS 20.0 software. Paired T-test was used to compare the means between two tests. The descriptive analysis also was conducted on the data. As for the interviews, they were verbatim transcribed by the researchers. The verbatim transcripts were analysed through thematic analysis and all major themes relating to their experiences using the Bar Model were taken as the results of the interview.

\section{RESULTS AND DISCUSSION}

Performance level for most of the participants on pre-test was low. There were 29 participants that achieved marks in the range from 0 to 4 and only 3 participants were able to achieve a medium level where their marks ranging from 5 to 7 . Through a deep checking on the participants' written works which were the solution to pre-test questions, the researchers discovered that participants could not solve the questions well. They could not give a complete solution for each question. They were unable to answer all the pre-test questions within the stipulated time. Based on the researchers' observations, strategies used by the participants were not suitable for answering the questions. The mean pre-test score was 2.89. It shows that most of the participants were categorised in the low-level of performance. The highest score for pre-test was 6 and the lowest score was 1 . None of the participants achieved a high level of performance.

Comparing to that pre-test, the post-test results showed the less number of participants with a low score decreasing from 29 to 7 . As there were only 3 participants achieved a medium performance level for pre-test, the post-test result showed a significant increase in a total number of participants in that level which was 15 . Post-test results also showed that there were 10 participants got scores in the range of 8 to 10 who can be grouped in the high-performance level. This result shows a dramatic change in participants' performance as there were previously none participants scored the high-performance level in the pre-test. Figure 1 shows a sample of the problem-solving questions and its solution of the pre-test and Figure 2 shows a sample of the problem-solving questions and its solution of the post-test. In Figure 1, the question was about the number of clothes donated by three different societies for the flood victims. The given information was the particular number of clothes donated by two societies and the total clothes received. Students were asked to calculate the number of clothes donated by the other society. Similarly, in Figure 2, the question was about the number of coloured papers (red, blue and yellow) used by Noraini. The given information was the particular number of blue and red papers used up and the total number of all the coloured papers. Students were asked to 


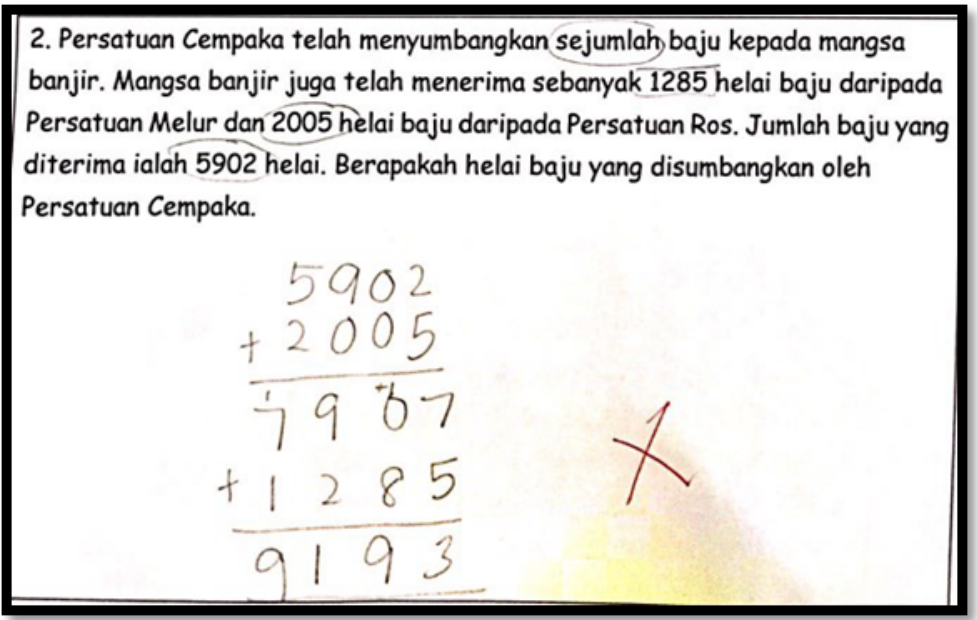

Figure 1. Pre-test problem-solving sample question and its solution

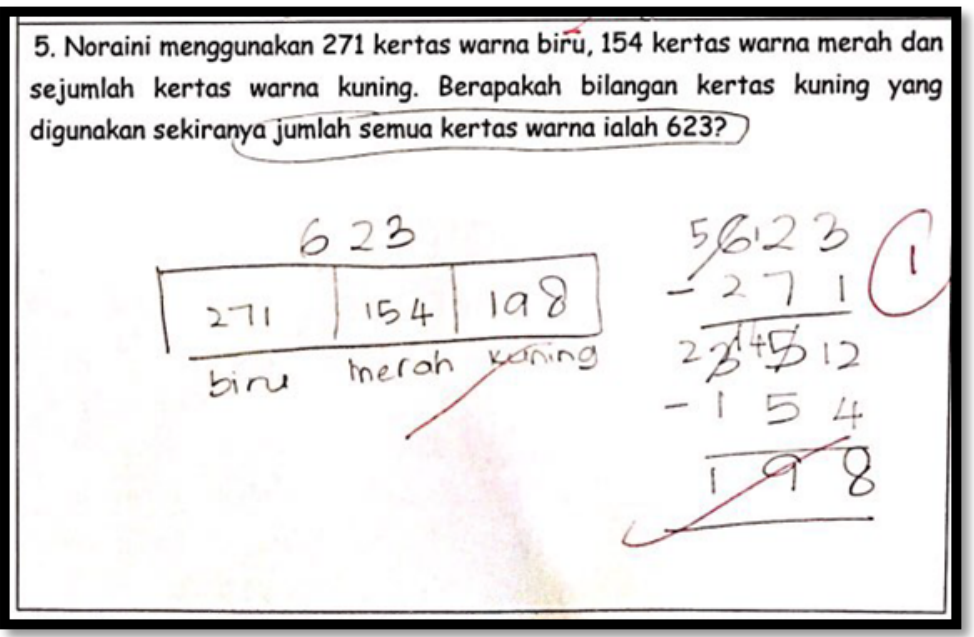

Figure 2. Post-test problem-solving sample question and its solution

Table 1. Summary of participants' performance level for pre-test and post-test

\begin{tabular}{lccc}
\hline Performance level (marks) & Low (0-4) & Medium (5-7) & High (8-10) \\
\hline Pre-test & 29 participants & 3 participants & none \\
\hline Post-test & 7 participants & 15 participants & 10 participants \\
\hline
\end{tabular}

calculate the number of yellow paper used by Noraini. It could be seen in Figure 1 that the student did not comprehend the question and answered the question by just adding up the numbers. On the contrary, in Figure 2, the student developed and visualised his comprehension of the question through the bar drawing and performed the calculation based on the drawing. These examples prove that using the bar model could help students to develop and visualize their comprehension and enhance their skills of mathematical problemsolving.

Most of the participants performed better on the post-test in problem-solving comparing to that pre-test. The mean post-test score was 6.16. This result shows a significant increase in the mean score from the pretest to post-test. The results indicate that there is a big increase in numbers of the participants' performance in problem-solving after the implementation of Bar Model. Table 1 shows the summary of the results.

Table 2 shows the analysis results using SPSS for the paired samples t-test of pre-test and post-test. The results showed that the significant value known as the p-value is 0.00 . Thus, it is a very small probability that this result occurring by chance, under the null hypothesis of no difference. The null hypothesis is rejected since $\mathrm{p}=0.00$. Olga (2010) who studied a visualisation strategy named model-drawing strategy to solve word 
Table 2. Paired Samples Test for Pre-test and Post-test

\begin{tabular}{|c|c|c|c|c|c|c|c|c|}
\hline & \multicolumn{5}{|c|}{ Paired Differences } & \multirow{3}{*}{$\mathbf{t}$} & \multirow{3}{*}{$\mathbf{d f}$} & \multirow{3}{*}{$\begin{array}{l}\text { Sig. }(2- \\
\text { tailed) }\end{array}$} \\
\hline & \multirow[t]{2}{*}{ Mean } & \multirow{2}{*}{$\begin{array}{c}\text { Std. } \\
\text { Deviation }\end{array}$} & \multirow{2}{*}{$\begin{array}{l}\text { Std. Error } \\
\text { Mean }\end{array}$} & \multicolumn{2}{|c|}{$\begin{array}{c}95 \% \text { Confidence Interval } \\
\text { of the Difference }\end{array}$} & & & \\
\hline & & & & Lower & Upper & & & \\
\hline Pair 1 PreTest-PostTest & -3.281 & 3.072 & .543 & -4.389 & -2.174 & -6.043 & 31 & .000 \\
\hline
\end{tabular}

problems also shared the same implication. The model drawing gives students a clear procedure for comprehending and executing problems. Therefore, it can be concluded that there was a significant difference in students' achievement in mathematics problem solving after applying the Bar Model strategy. Thus, the study clearly showed that the Bar Model strategy gives positive impacts on the participants' achievement in mathematical problem-solving.

In exploring experiences of students in applying this bar model technique in mathematical problemsolving, nine participants were interviewed based on their performance level on the post-test. Three participants from each performance level of low, moderate and high were chosen and interviewed by the researchers.

An excerpt of the interview with one of the participants from low-performance level:

Please teach me again later how to use the technique until I understand. I also want to draw like other friends. I want to use this technique to solve problems because it looks interesting.

An excerpt of the interview with one of the participants from moderate-performance level:

There are questions that I do not understand how to apply this technique. But I can answer most of the questions. It's easy to use this technique.

An excerpt of the interview with one of the participants from high-performance level:

The technique is very helpful. I could understand it very well and easy for me to solve the problems.

The interview transcripts were analysed through thematic analysis. There were two major themes deduced from the analysis. The first theme was the level of understanding. The extent to which the technique is beneficial to the students depends on their understanding on using it. The second theme was the motivation. Although they initially could not understand the bar model, they were attracted and interested to use the technique and tried to solve the post-test questions. The bar model strategy motivated them to solve the questions. Based on the interviews conducted, all participants including the low-performance level students were interested and motivated to use the bar model in mathematical problem-solving.

This study proves that it is essential for teachers to vary their strategies and methodologies for teaching problem-solving. Students cannot solve the problems well if they do not have a variety of problem-solving skills. Hattikudur, Sidney, \& Alibali (2016) stated in their study that the benefits of learning multiple procedures are great when students compare those procedures. They have alternatives when they are planning and searching for solutions. Exposure to different strategies nurtures meaningful ways of learning mathematics (Intaros, Inprasitha, \& Srisawadi, 2013).

Other than that, teachers should be encouraged to use visualisation techniques for teaching mathematical problem-solving. According to Alsina and Nelsen (2006), the visualisation technique may be a tool to develop intuition, to start solving a problem or a natural way to identify concepts. As mentioned earlier, the bar model is one of the visualisation techniques used in mathematical problem-solving. Findings of this study have shown that the students were interested and motivated in applying this bar model in solving mathematical problems. The study also shows that the bar model visualisation technique helps to enhance students' mathematical problem- solving skills.

\section{CONCLUSION}

The results of this study indicate that the bar model could be a useful strategy to help students to improve their mathematical problem-solving skills. The bar model helps students to understand and solve problems better by visualising and making sense of a problem using the rectangular bar. As a matter of fact, the findings from the test and interview conducted have revealed that students could overcome their dislike towards word 
problem-solving questions by using the bar model method. The results showed that there was a significant difference in students' achievement after the implementation of the model. There were positive impacts not only on the results but also on the participants' attitude towards the questions. This method helped students to build and elevate their confidence as they were excited and courageous enough to try answering all the questions given. The use of bar model is also beneficial to students as it motivates them to answer the questions. The bar model can be a major help in learning for long-term mathematics success. It should be emphasized in education as it contributes to students' learning by bringing positive impacts to the students. It enhances students' understanding regarding problem-solving as it helps to visualise and solve the problems. Other than that, it can be applied to many mathematical operations and topics. It can help students to apply these concepts to a variety of challenging word problems questions. Lastly, it helps to make the learning of mathematics more meaningful and easier. Thus, it is recommended for teachers to use the bar model technique in teaching mathematical problem-solving as the technique provides engaging and purposeful experiences throughout the learning process.

\section{Disclosure statement}

No potential conflict of interest was reported by the authors.

\section{Notes on contributors}

Sharifah Osman - Universiti Teknologi Malaysia, Malaysia.

Che Nurul Azieana Che Yang - SK Taman Perling, Johor, Malaysia.

Mohd Salleh Abu - Universiti Teknologi Malaysia, Malaysia.

Norulhuda Ismail - Universiti Teknologi Malaysia, Malaysia.

Hanifah Jambari - Universiti Teknologi Malaysia, Malaysia.

Jeya Amantha Kumar - Universiti Sains Malaysia, Malaysia.

\section{REFERENCES}

Alsina, C., \& Nelsen, R.B. (2006). Math Made Visual (Creating Images for Understanding Mathematics). United States of America: The Mathematical Association of America. https://doi.org/10.5948/UP09781614441007

Arslan, C., Yavuz, G., \& Deringol-Karatas, Y. (2014). Attitudes of Elementary School Students towards Solving Mathematics Problems. Istanbul University Hasan Ali Yucel. Procedia Social and Behavioral Sciences, 152, 557-562. https://doi.org/10.1016/j.sbspro.2014.09.243

Azizah, A, Rohani, A. T., \& Mokhtar, N. (2010). Visual Representations in Mathematical Word Problem Solving Among Form Four Students in Malacca. International Conference on Mathematics Education Research 2010 (ICMER 2010), 8, 356-361.

Bluman, A. (2005). Math Word Problems Demystified: A Self-Teaching Guide. McGraw-Hill.

Edens, K., \& Potter, E. (2007). The Relationship of Drawing and Mathematical Problem Solving: Draw for Math Tasks. A Journal of Issues and Research, 48, 282-298.

Government of Ireland. (1999). Mathematics Teacher Guidelines: Primary School Curriculum. Dublin: The Stationery Office

Hamadneh, I. M., \& Al-Masaeed, A. (2015). Math teachers' attitudes towards photo math application in solving mathematical problem using mobile camera. Educational Research and Reviews, 10(14), 1930-1936. https://doi.org/10.5897/ERR2015.2181

Han, O. B., Noor, D. A. H., Rio, S. S., \& Zaleha, A. (2013). Computer-Based Courseware in Learning Mathematics: Potentials and Constraints. 13 th International Educational Technology Conference. Procedia - Social and Behavioral Sciences.

Hattikudur, S., Sidney, P. G., \& Alibali, M. W. (2016). Does Comparing Informal and Formal Procedures Promote Mathematics Learning? The Benefits of Bridging Depend on Attitudes Toward Mathematics. Journal of Problem Solving, 9, 13-27. https://doi.org/10.7771/1932-6246.1180

Hofer, C. (2015). The Introduction of The Singapore Bar Model in Year 1 Problem Solving: A Personal Reflection. University of Cumbria, 2(2), 107-117. 
Intaros, P., Inprasitha, M., \& Srisawadi, N. (2014). Students' Problem Solving Strategies in Problem Solving - Mathematics Classroom. $5^{\text {th }}$ World Conference on Educational Sciences. Procedia - Social and Behavioral Sciences, 116, 4119-4123. https://doi.org/10.1016/j.sbspro.2014.01.901

Kamariah, A. B., Jennifer, W., \& Janette, B. (2016). Young Children's Drawings in Problem Solving. Mathematics Education Research Group of Australasia, 86-93. Adelaide: MERGA.

Marshall Cavendish. (2008). Problem Solving in Singapore Math (Math in Focus). Houghton Mifflin Harcourt.

Mooney, C., Briggs, M., Fletcher, M., Hansen, A., \& McCullouch, J. (2014). Primary Mathematics: Teaching Theory \& Practice. London: SAGE Publications Ltd.

Moussavi, M. (1998). Mathematical modelling in engineering education. FIE '98. 28th Annual Frontiers in Education Conference. Moving from "Teacher-Centered" to "Learner-Centered" Education. Conference Proceedings (Cat. No.98CH36214), 2, 963-966. https://doi.org/10.1109/FIE.1998.738891

Olga, J. (2010). Model-Drawing Strategy to Solve Word Problems for Students with LD. Miami: IARLD Conference, The Frostig Center.

Osman, S., Abu, M. S., Mohammad, S., \& Mokhtar, M. (2016). Identifying Pertinent Elements of Critical Thinking and Mathematical Thinking Used in Civil Engineering Practice in Relation to Engineering Education. The Qualitative Report, 21(2), 212-227.

Pehkonen, E., Naveri, L., \& Laine, A. (2013). On Teaching Problem Solving in School Mathematics. CEPS Journal, 3(4).

Phonapichat, P., Wongwanich, S., \& Sujiva, S. (2013). An Analysis of Elementary School Students' Difficulties in Mathematical Problem Solving. Procedia-Social and Behavioral Sciences, 116, 3169-3174 https://doi.org/10.1016/j.sbspro.2014.01.728

Thirunavukkarasu, M., \& Senthilnathan, S. (2014). Effectiveness of Bar Model in Enhancing the Learning of Mathematics at Primary Level. International Journal of Teacher Educational Research (IJTER) Bharathidasan University, 3(1).

Verschaffel, L., \& De Corte, E. (1993). A Decade of Research on Word Problem Solving in Leuven: Theoretical, Methodological, and Practical Outcomes. Educational Psychology Review, 5(3), 239-256. Retrieved from http://www.jstor.org/stable/23359246 https://doi.org/10.1007/BF01323046

Vula, E., \& Kurshumlia, R. (2015). Mathematics Word Problem Solving Through Collaborative Action Research. Journal of Teacher Action Research, 1(2), 34-46. 